\title{
Pathogenesis and Bone Resorption in Acquired Cholesteatoma: Current Knowledge and Future Prospectives
}

\author{
Mahmood A. Hamed ${ }^{1,2} \cdot$ Seiichi Nakata ${ }^{1} \cdot$ Ramadan H. Sayed ${ }^{2} \cdot$ Hiromi Ueda $^{3} \cdot$ Badawy S. Badawy $^{2}$ \\ Yoichi Nishimura ${ }^{1}$ Takuro Kojima ${ }^{1}$. Noboru Iwata ${ }^{1}$ Ahmed R. Ahmed ${ }^{4} \cdot$ Khalid Dahy $^{2} \cdot$ Naoki Kondo $^{5} \cdot$ Kenji Suzuki $^{1,6}$ \\ ${ }^{I}$ Department of Otolaryngology, Second Hospital, Fujita Health University School of Medicine, Nagoya, Japan; ${ }^{2}$ Department of Otolaryngology, \\ Sohag Faculty of Medicine, Sohag University, Sohag, Egypt, ${ }^{3}$ Department of Otolaryngology, Aichi Medical University, Nagakute, Japan; \\ ${ }^{4}$ Department of Pathology, Sohag Faculty of Medicine, Sohag University, Sohag, Egypt; ${ }^{5}$ Department of Pathology, Second Hospital, Fujita \\ Health University School of Medicine, Nagoya, Japan; ${ }^{6}$ Department of Otolaryngology, Yonaha General Hospital, Kuwana, Japan
}

Cholesteatoma is a cystic non tumorous lesion of the temporal bone that has the ability to destroy nearby structures by its power to cause bone resorption and as a result, fatal complications prevail. We aimed to conduct a comprehensive review for pathogenesis of acquired cholesteatoma, bone resorption mechanisms, and offer a future vision of this serious disease. We have reviewed different theories for pathogenesis of acquired cholesteatoma including the most relevant and updated ones with special emphasis on the mechanisms of bone resorption through Medline/PubMed research using the keywords 'aetiopathogenesis, bone resorption, acquired cholesteatoma, temporal bone, and cytokines.' In order to strengthen our study, we searched the reference lists of identified reviews. Cholesteatoma is a subject of debate among otolaryngologists since it was prescribed firstly. Over many decades, several theories were postulated for aetiopathogenesis of cholesteatoma with a tendency to follow more than one theory to explain the proper nature of that disease. Until now, the mechanism of bone resorption has yet to be more clarified. In the last century, a leap has occurred in the field of biomolecular cholesteatoma research which improved our knowledge about its pathophysiology and bone destructive mechanism. However, surgery is still the only available treatment. We conclude that discovery of new therapeutic choices for cholesteatoma other than surgery by the use of anti-growth, anti-proliferative, apoptotic agents as well as medications that antagonize osteoclastogenesis should be the main concern in the future clinical and experimental research work. Also, searching for predictors of the aggressiveness of cholesteatoma can affect the timing of intervention and prevent occurrence of complications.

Keywords. Pathogenesis; Bone Resorption; Cholesteatoma; Acquired; Temporal Bone; Cytokines

\section{INTRODUCTION}

Cholesteatoma is a non-neoplastic lesion of the temporal bone that can gradually expand and cause complications by bone ero-

\footnotetext{
- Received October 22, 2015

Revised January 11, 2016

Accepted January 13, 2016

- Corresponding author: Seiichi Nakata

Department of Otolaryngology, Second Hospital, Fujita Health University School of Medicine, 3-6-10 Otobashi, Nakagawa-ku, Nagoya 454-8509, Japan

Tel: +81-52-323-5647, Fax: +81-52-331-6843

E-mail: seisay@fujita-hu.ac.jp
}

sion of the nearby structures. Until now, its pathogenesis is a matter of controversy and surgery is the only available treatment [1]. Du-verney in 1683 was the first to describe a temporal bone tumor probably matching with cholesteatoma. This was followed by pathologic description of cholesteatoma by Cruveilhier in 1829 as a pearly tumor. Then the German anatomist Johannes Muller in 1838 gave it the name 'cholesteatoma' which is completely incorrect being neither a tumor nor contains fat or cholesterol crystals. Nevertheless, it is still the most popular term until now. Other terms were given, including margaritoma, by Craigie in 1891, epidermal cholesteatoma by Cushing in 1922, epidermoid by Critchley and Ferguson in 1928, and kera-

Copyright @ 2016 by Korean Society of Otorhinolaryngology-Head and Neck Surgery

This is an open-access article distributed under the terms of the Creative Commons Attribution Non-Commercial License (http://creativecommons.org/licenses/by-nc/4.0)

which permits unrestricted non-commercial use, distribution, and reproduction in any medium, provided the original work is properly cited. 
toma by Shuknecht in 1974 [2-5]. The annual incidence of cholesteatoma is greatly variable being dependent on plenty of factors including environmental, socioeconomic, ethnic, genetic, anatomical, and physiological ones [6]. Broadly speaking, it ranges from 9 to 12.6 per 100,000 in adults and 3 to 15 per 100,000 in children with male predominance $[1,4,6]$. Caucasian people show the highest prevalence (12.6 per 100,000) followed by Africans whilst the lowest prevalence is seen among Eskimos, possibly due to larger nasopharynx and wider auditory tube $[1,4]$. The progressive bone erosion made by cholesteatoma can lead to permanent hearing loss, vestibular dysfunction, facial palsy, and more fatal intracranial complications [7]. It was found that a complex process with integration of both molecular and cellular events could play the major role in cholesteatoma formation, growth as well as its destructive pattern $[1,8,9]$.

\section{METHODS}

We searched various literature reviews and original research referring to pathogenesis and bone resorption in acquired cholesteatoma in Medline/PubMed databases using the keywords 'aetiopathogenesis, bone resorption, acquired cholesteatoma, temporal bone, and cytokines.' Non-related and non-English articles were excluded. Critical appraisal of the remaining articles was done by 6 experienced reviewers with the most recent and best evidence currently available ones were chosen.

\section{RESULTS}

First, 320 articles were found. After exclusion of non-related and non-English articles, 204 articles were remained. After further scrutiny, 140 articles were finally selected (Fig. 1).

\section{DISCUSSION}

It is generally accepted that cholesteatoma is divided into two main categories, congenital and acquired, and the latter is fur-

\section{H I}

- We have reviewed all theories that explain the pathogenesis of acquired cholesteatoma.

- Different mechanisms for bone resorption in that disease were also described in details.

- No single theory is enough to explain all events in acquired cholesteatoma.

- Experimental research should go on to provide better understanding and non-surgical therapy.

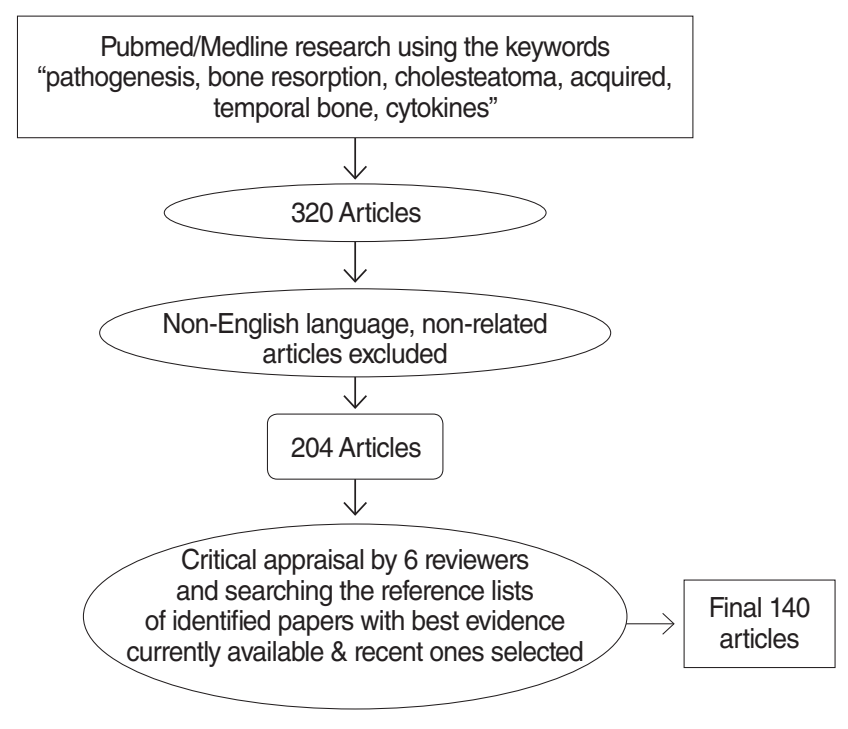

Fig. 1. Methods of papers' selection in our review.

ther divided into primary (attic retraction without previous history of otitis media $[\mathrm{OM}]$ or tympanic membrane [TM] perforation), secondary (epithelial migration through perforated TM), and tertiary (following trauma or antecedent middle ear inflammation) [10]. Theories of acquired cholesteatoma include.

\section{Metaplasia theory}

First suggested by von Trolsch in 1864 and Wendt in 1873 [1]. According to this theory, the low cuboidal epithelium of the middle ear changes into squamous epithelium under the effect of chronic inflammation. However, there was neither histologic nor experimental proof supported this theory [11]. In addition, the differences observed in the cytokeratin $(\mathrm{CK})$ profile between cholesteatoma epithelium and middle ear epithelium were also against this theory [12]. Finally, several studies have proved that cholesteatoma epithelium was ectodermal in origin derived from the external canal and TM and not metaplastic from the middle ear epithelium which is entirely endodermal [13-15]. Nevertheless, Kuijpers et al. [16] found that a true change in the differentiation of the middle ear epithelium had occurred with loss of simple epithelial CKs and appearance of CKs characteristic of stratified and cornifying epithelia. They concluded that CK map can't be used as a reliable detector for the origin of cholesteatoma [16].

\section{Hyperplasia (proliferation) theory}

First proposed by Lange in 1925, and supported by Reudi in 1978 [1]. Secondary to an inflammatory reaction of prussak's space, the basal layer of the pars flaccida started to form epithelial pseudopods and microcysts that invaginate into the underlying basement membrane and subepithelial space to form epithelial cones which then become filled with keratin. The basal lamina later regains itself. Keratinization within the epithelial cones 
leads to formation of microcholesteatomas. Papillary ingrowth of the squamous epithelium demonstrated by light and electron microscopy in patients with adhesive OM supported this theory [17]. This sequence of events may explain the occurrence of intratympanic cholesteatomas without retraction pocket or TM perforation $[18,19]$. In complement with this theory and through clinical and postmortem histopathologic analysis, Sudhoff and Linthicum [20] reported a case of acquired cholesteatoma behind an intact TM after recovered TM retraction.

\section{Invasion (immigration) theory}

First prescribed by Habbermann in 1988 and Bezold in 1890 [1]. This theory depends upon migration of the keratinizing squamous epithelium from the outer surface of the TM and external canal into the middle ear cavity through iatrogenic, traumatic perforation or following an attack of OM. This theory was proved by experimental studies on guinea pig bulla [11]. Observing an identical morphology on electron microscopy between the skin and cholesteatoma supported migration theory [21]. Furthermore, a similarity was found in the CK distribution of the external canal skin and cholesteatoma in contrast to the middle ear epithelium $[12,22]$. Nevertheless, this theory could not explain the occurrence of cholesteatoma in ears without TM perforation which is a common situation [23].

\section{Implantation theory}

This theory implies formation of cholesteatoma as a result of accidental impaction of squamous epithelium into the tympanic cavity following ear surgery (iatrogenic), accidental trauma, or blast injury $[24,25]$.

\section{Invagination (retraction pocket) theory}

Originally described by Wittmack, in 1933 and it remained the most widely accepted until now $[5,23]$. This theory assumed that primary acquired cholesteatoma was preceded by retraction pocket in the region of pars flaccida caused by negative pressure of the middle ear due to variety of factors like Eustachian tube malfunction, habitual sniffing, or small mastoid volume [26-28]. This was followed by accumulation of exfoliated keratin in this pocket with resultant cholesteatoma formation. The theory was supported experimentally by formation of cholesteatoma in $75 \%$ of Mongolian gerbils following bilateral Eustachian tube obstruction by electrocautery and also by higher incidence of cholesteatoma among patients with cleft palate in whom the Eustachian tube was malfunctioning [29,30]. Recently, Jackler et al. [23] criticized the invagination theory in several respects. Their criticism was depending on observing the results of other studies and can be summarized in the following points: first, the occurrence of cholesteatoma was not reduced after cleft palate repair or insertion of ventilation tubes in cleft palate patients [31,32]. Second, observing healthy and well-functioning Eustachian tube in some cholesteatomatous ears. Third, surgical oblit- eration of Eustachian tube after some skull base and otologic surgeries didn't lead to cholesteatoma formation [33]. Fourth, in a study done by Roland et al. [34], the insertion of ventilation tympanostomy tubes was not effective in lowering the incidence of cholesteatoma in children. Finally that the negative middle ear pressure, although it can lead to TM retraction, it doesn't have enough power to maintain further progression of cholesteatoma pouch [23].

\section{Selective epitympanic dysventilation syndrome}

In complement with the invagination theory, Marchioni et al. [35-37] put a hypothesis to explain the pathogenesis of epitympanic cholesteatoma and called it selective epitympanic dysventilation syndrome. It was based on previous studies performed by Palva et al. [38,39] concerning the impact of anatomic factors of the middle ear on epitympanic ventilation and genesis of middle ear inflammatory diseases. Through careful examination of the detailed anatomy of mucosal folds and ligaments of the epitympanic space via otoendoscopy during surgery for patients with non-cleaning attic retraction pockets or definite attic cholesteatomas versus a control group with non-cholesteatomatous $\mathrm{OM}$, they found that the attic retraction pocket and attic cholesteatoma could occur in the presence of normal Eustachian tube function proved by tympanometry and William's test. This is due to complete blockage of the tympanic isthmus by mucosa or granulations and complete tensor fold that finally lead to complete separation of the attic space from the mesotympanum which in turn hinder attic ventilation with resultant negative pressure only limited to this area and subsequent cholesteatoma formation [35-37].

\section{Cholesteatoma as a wound healing process}

Current concepts postulate that cholesteatoma may be 'a defective wound healing process.' But in cholesteatoma, inflammatory and proliferative stages predominated whereas the maturation stage was never achieved [9]. The inflammation of middle ear mucosa starts the wound healing process in a trial to correct tissue injury but persistence of inflammation causes permanent wound healing in the perimatrix (subepithelial connective tissue), with proliferation of both the matrix and perimatrix and release of inflammatory cytokines. This concept was supported by immunohistochemical studies especially on transforming growth factor (TGF)- $\beta$ which has an important role in both normal and abnormal wound healing $[9,40]$. However, this theory cannot explain the fact that in many cases persistent inflammation with granulation tissue formation occurs without cholesteatoma formation.

\section{Mucosal traction theory}

The most recent hypothesis for cholesteatoma pathogenesis was suggested by Jackler et al. [23] in 2015. The main principle of this theory is based upon observing the mucosal migration on 
the inner surface of the TM and mucociliary movement of middle ear mucosa. According to this theory, 'mucosal coupling' which means the interaction between the medial aspect of the $\mathrm{TM}$ and the opposing lateral aspect of the auditory ossicles is the motivating force for an epithelial pouch to form with subsequent cholesteatoma formation. The authors supported this theory by both animal and human studies through careful watching of mucosal migration pattern and mucociliary movement of the middle ear mucosa. Animal study showed that the direction of mucosal migration from the posterior part of the pars tensa was posterosuperiorly whereas the mucosa of the anterior part migrated in a radial direction towards the annulus. Following this theory, cholesteatoma is basically a mucosal disease. The authors suggested therapeutic strategies based on their presupposition. Medications that can interfere with or inhibit the 'coupling' occurring between the two opposing mucosal surfaces like the use of anti-viscosity pharmaceutical agents which allow lubrication of those surfaces or insertion of biological membrane can inhibit pouch formation. In addition, reducing the ciliary activity on the medial surface of the TM by laser for example can also prevent pouch formation and progression [23]. According to many authors, combination of the above theories is the most likely presupposition to explain various biologic characters of cholesteatoma $[1,5,41]$. These theories are summarized in Table 1 .

\section{HISTOLOGY OF CHOLESTEATOMA}

Histologically, cholesteatoma is formed of 3 layers; matrix, perimatrix, and cystic content. The matrix is formed of epithelial layers identical to that of the skin but in greater quantity. The perimatrix is formed of variable thickness of subepithelial loose connective tissue with collagen fibers, fibrocytes and other inflammatory cells such as lymphocytes, histiocytes, plasma cells, and neutrophils. Finally, cystic content is formed of keratin lamellae [42]. The matrix exhibited different features which were positively correlated to each other including atrophy, acanthosis, basal cell hyperplasia, and epithelial cones formation into the perimatrix [43]. The degree of inflammation of the perimatrix is positively related to its thickness [44].

\section{MECHANISMS OF BONE RESORPTION IN CHOLESTEATOMA}

Despite being the most rigid bone of the human body, the labyrinth can be stimulated by variety of factors of bone erosion $[45,46]$. Bone erosion can occur in both chronic OM with or without cholesteatoma but more common in cholesteatomatous type $[47,48]$. A recent study reported that labyrinthine fistula was the commonest intracranial complication of OM especially with cholesteatomatous type [49] (Fig. 2).

\section{Pressure theory}

In vitro studies revealed that osteoclastic bone resorption could occur in the sites where adequate pressure was induced directly or transmitted to the tympanic cavity with or without presence of cholesteatoma [50-53].

\section{Chemical activity and bone resorption}

Chemical activity of cholesteatoma in bone resorption has been suggested since 1950s. Areas of bone destruction could be seen at the site of rupture of cholesteatoma $[54,55]$. Hydroxyapatite, an inorganic bone component is highly insoluble under physiologic $\mathrm{pH}$ environment, but solubility dramatically increases as

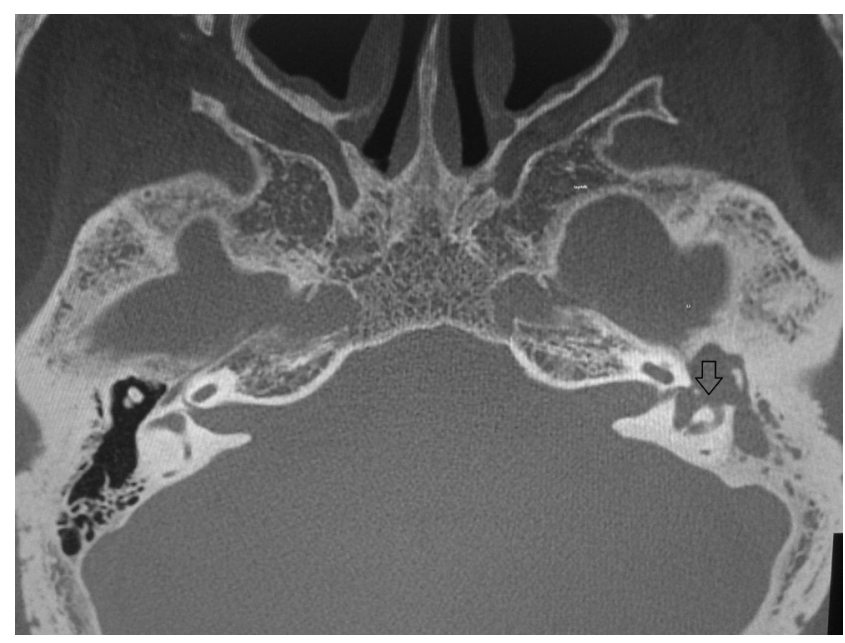

Fig. 2. Left cholesteatomatous otitis media complicated by left lateral canal fistula (arrow).

Table 1. Theories of pathogenesis of acquired cholesteatoma as reported in the literature up to 2015

\begin{tabular}{ll}
\hline Theory name & Authors \& years \\
\hline Metaplasia & Von Trolsch (1864) and Wendt (1873), cited by Olszewska et al. (2004) [1] \\
Hyperplasia & Lange (1925) and Reudi (1978), cited by Olszewska et al. (2004) [1] \\
Invasion (immigration) & Habbermann (1988) and Bezold (1890), cited by Olszewska et al. (2004) [1] \\
Implantation & Wullstein and Wullstein (1980) [24], McKennan and Chole (1989) [25] \\
Invagination (retraction pocket) & Wittmack (1933) [5,23] \\
Wound healing & Albino et al. (1998) [9], Huisman et al. (2008) [40] \\
Epitympanic dysventilation & Marchioni et al. (2010, 2011, 2013) [35-37] \\
Mucosal traction & Jackler et al. (2015) [23]
\end{tabular}


the $\mathrm{pH}$ is lowered [56]. Nguyen et al. [55] investigated the role of $\mathrm{pH}$ in bone resorption in cholesteatoma and found that the $\mathrm{pH}$ of keratin debris was acidic and lower than the antrum mucosa. So, they concluded that acidic $\mathrm{pH}$ in cholesteatoma may be one of the factors that promote bone erosion by decalcification of the adjacent bony structures [55].

\section{Role of bacterial infection, bacterial biofilms, and lipopolysac- charide}

Bacterial biofilms were found to be very common in chronic suppurative $\mathrm{OM}$ and middle ear cholesteatomas $[57,58]$. The keratin layer of cholesteatoma is an ideal environment for biofilm production. The presence of bacterial biofilms in cholesteatoma mediates the host response in the form of chronic inflammation, proliferation, and bone resorption [59]. A positive correlation was found between biofilm formation and presence of cholesteatoma [60]. Concerning bacterial infection, pseudomonas aeruginosa $(\mathrm{PA})$ is the most common organism isolated from infectious middle ear diseases followed by staphylococcus aureus and other gram positive aerobes. PA produces lipopolysaccharide (LPS) which is present in higher concentration in chronic OM with cholesteatoma than those without cholesteatoma. LPS stimulates osteoclastogenesis directly from mononuclear osteoclast precursors. Furthermore, it stimulates production of interleukin (IL)-1 $\beta$, IL-6, prostaglandin (PG) E2, and tumor necrosis factor alpha (TNF- $\alpha$ ) from macrophages and monocytes with resultant increase in inflammatory activity [8,61-65]. Jung et al. [66] performed an experimental study to investigate the role of $\mathrm{PA}$ in the aggressiveness of induced cholesteatoma in gerbils and found that infected cholesteatomas showed more expansion and became more aggressive than uninfected control subjects.

\section{Inflammatory mediators}

Inflammatory mediators initiate chronic inflammation and recruitment of osteoclasts and hence induce bone resorption in cholesteatoma [48].These mediators include.

\section{RANK-RANKL-OPG system}

Recently, it was proved that the receptor activator of nuclear factor (NF)-kappa B, receptor activator of NF-kappa B ligand and osteoprotegerin (RANK-RANKL-OPG) system plays a key role in bone metabolic disorders [67], including bone resorption in the middle ear cholesteatoma. By immunohistochemistry (IHC), Jeong et al. [68] concluded that the RANKL, an osteoclast activator, being highly represented in cholesteatoma tissues as compared to control skin tissues, had a vital role in bone resorption in cholesteatoma and RANKL/OPG ratio was considered to be a reliable index for bone erosion in cholesteatoma. Furthermore, activating NF-kappa B in osteoclast precursors by adding substance $P$ enhanced osteoclastogenesis in vitro [69].

\section{Neurotransmitters}

They include neuropeptides and vasoactive amines. Since the aural periosteum has very rich autonomic and nerve supply, some authors suggest that neural mechanism may play an active role in bone resorption. This issue needs more investigation $[7,70]$.

\section{Role of nitrous oxide}

Nitrous oxide (NO) is a potentially important mediator of bone resorption. Jung et al. [71,72] studied the role of NO in cholesteatoma induced bone resorption through both in vitro and in vivo experiments. They found that all nitric oxide synthase (NOS) isoforms (I, II, and III) were expressed in an in vivo model of cholesteatoma induced bone resorption with particular upregulation of NOS III. Furthermore, exogenously administered nitric oxide enhanced osteoclast activation in vitro [71,72].

\section{Enzymatic activity in cholesteatoma}

Many enzymes were investigated in the process of bone erosion. In the presence of inflammation, Collagenase attacks the intact collagen molecule, making it susceptible to further digestion by other proteases with subsequent bone resorption [73]. The production of collagenase was enhanced by the interaction between epithelial cells and mesenchymal cells [74]. Another factor is the plasminogen cascade which has a role in bone resorption in chronic OM especially cholesteatoma due to presence of keratinizing epithelium [75]. Additionally, higher levels of N-acetyl$\beta$-hexosaminidase (HEX) were found in cholesteatoma tissues compared to retroauricular skin of the same patients. These results attracted the attention towards the role of HEX in the destructive behavior of cholesteatoma [76,77]. Furthermore, Olszewska et al. [78] found higher serum concentration of HEX, $\beta$-glucuronidase, and $\beta$-galactosidase with resultant increase in glycoconjugate catabolism in the serum of cholesteatoma patients in comparison to healthy subjects. Finally, Hansen et al. [79] found that cysteine proteinase cathepsin K was strongly expressed in cholesteatoma tissues particularly in osteoclasts at the site of bone destruction.

\section{Proliferation markers and relation to bone destruction}

Cholesteatoma is a disorder of epithelial proliferation [80]. It was suggested that cholesteatoma had different biologic nature from that of the normal epithelial cell, especially in the basal cells [21]. Hyperproliferation of keratinocytes with abundant production of keratin in the tympanic cavity under the effect of chronic inflammation is the characteristic hallmark of cholesteatoma [81]. This hyperproliferative activity can be used as a marker or predictor for the aggressive potential of cholesteatoma. Mallet et al. [82] used MIB1 monoclonal antibody to measure proliferative activity in 91 cholesteatoma tissues and found positive correlation of such activity to the aggressiveness of cholesteatoma and to the degree of inflammation. This was more 
pronounced in children in whom cholesteatomas were more aggressive than adults [82]. Another study conducted by Macias et al. [83] investigated the role of amphiregulin as a biological marker for cholesteatoma activity. Amphiregulin gene expression was found higher in cholesteatoma tissues as compared to skin control tissues and the increased expression was inversely related to the stage of disease progression [83]. Many other proliferation markers were discussed in the literature including $\mathrm{CK}$ $13 \& 16$, epidermal growth factor, IL-1, TGF- $\alpha$, keratinocyte growth factor, proliferating cell nuclear antigen, tolemerase, and Ki-67. The authors emphasize that the proliferative activity and the expression of these markers in cholesteatoma tissues were higher than that of the normal epidermis or non-cholesteatomatous OM [84-95].

\section{Role of prostaglandins}

Eicosanoids are arachidonic acid metabolites. They include PGs and leukotrienes which are formed by cyclooxygenase and lipoxygenase respectively. PGs play an active role in the pathogenesis of chronic OM with bone resorption. Levels of PG E2 and thromboxane $\mathrm{E} 2$ were found to be higher in cholesteatoma than in granulation tissue [96]. An experimental in vitro study revealed that endotoxin and PG E2 stimulate the growth of epidermal basal cells of cholesteatoma [97].

\section{Cytokines}

Cytokines are released at the site of infection by variety of inflammatory cells and play a significant role in immune response and inflammation [62]. They have a role in proliferative activity, angiogenesis, and destructive behavior of cholesteatoma. Among the involved cytokines and considered to have an intimate relation with bone destruction are TNF- $\alpha$, IL-1, IL- 6 , matrix metalloproteinase 2 (MMP 2), and matrix metalloproteinase 9 (MMP 9) $[47,98-114]$.

Tumor necrosis factor alpha: TNF- $\alpha$ was produced by macrophages, monocytes as well as lymphocytes [115]. It is considered an autocrine growth modulator that stimulates osteoclast induced bone resorption and inhibits collagen synthesis by promotion of the activity of collagenases, acid phosphatases and proteases [116]. The role of TNF- $\alpha$ in bone destruction in cholesteatoma had been suggested by many authors. lino et al. found that cholesteatoma debris was a potent stimulus for production of TNF from cultured human monocytes/macrophages [117]. The serum levels of TNF- $\alpha$ as well as its level in cholesteatoma debris were found to higher in patients with cholesteatoma than controls and such levels are positively correlated with the degree of bone destruction $[103,106]$.

Interleukin-1: An osteoclast activating factor and it can induce fibroblasts to produce PGs and collagenase enzymes $[109,118]$. IL-1 $\alpha$ was overexpressed in cholesteatoma tissue and its expression was positively correlated with the activity of bone destruction of cholesteatoma and proliferation of granulation tissue
$[102,106]$.

Matrix metalloproteinase 2 and matrix metalloproteinase 9: They are group of proteolytic enzymes capable of degrading the extracellular matrix [119]. Higher expression of MMP 2 and MMP 9 in cholesteatoma tissue in comparison to the normal canal skin was proved by many authors and by the use of different techniques such as enzyme-linked immunosorbent assay, zymography, immunofluorescence, IHC, and reverse transcriptionpolymerase chain reaction for gene expression [104,107,111]. Furthermore, Juhasz et al. [111] revealed that increased expression of MMP 9 and tenascin was positively correlated with the aggressiveness of cholesteatoma. Thus, they could be used as a reference to detect the bone destructive capacity of cholesteatoma [111].

Other cytokines: Angiogenic growth factors such as fibroblast growth factor alpha, TGF- $\beta$, TGF- $\alpha$, and vascular endothelial growth factor. These cytokines play an essential role in the process of angiogenesis which maintains continuous migration of keratinocytes into the tympanic cavity and actively share in the destructive pattern of cholesteatoma [120]. Another cytokine is platelet derived growth factor which stimulates monocytes to produce osteoclast-like cells with subsequent resorption of devitalized bovine bone [121]. Also, granulocyte-macrophage colony stimulating factor was proved to have positive effect on the proliferating activity of basal keratinocytes [122].

\section{Bone morphogenic proteins}

Recently, bone morphogenic protein (BMP)-2 was investigated in the keratinocytes and fibroblasts of both external auditory canal (EAC) and cholesteatoma tissues. It was expressed in keratinocytes of the two comparison groups and highly expressed in the perimatrix fibroblasts of cholesteatoma group whereas it was not expressed in fibroblasts of normal EAC skin. Incubation of these fibroblasts with cholesteatoma tissue caused the transcription of BMP-2 [123]. Moreover, another prospective more recent study was conducted by Oger et al. [124] to investigate gene expression of BMPs, BMP2, BMP4, and BMP6 in 80 patients with chronic $\mathrm{OM}$ with and without cholesteatoma. The cholesteatoma group showed higher expression of BMPs, BMP2, and BMP6. Furthermore, BMPs positivity was significantly related with the bone destruction of all ossicles. Thus, it can be used as a marker for cholesteatoma activity in bone destruction [124].

\section{Apoptosis and apoptotic activity in cholesteatoma}

Loss of balance between apoptotic and antiapoptotic markers (cell death/proliferation) with favorable antiapoptotic activity in cholesteatoma can lead to its survival and expansion. It was found that cellular FLICE-like inhibitory protein, an antiapoptotic protein was upregulated in cholesteatoma epithelium as compared to normal skin without significant changes in p53, a well-known apoptotic protein. Also, the levels of galectin-3 were 
found to be significantly correlated with level of apoptosis and had a protective role against apoptosis activity in recurrent cholesteatoma. Apoptosis was found in the suprabasal layers of cholesteatoma epithelium but not found in the basal layers [125127]. A recent study showed that let 7a microRNA had a vital role in the in the inhibition of growth and invasion of cholesteatoma keratinocytes via downregulation of $\mathrm{miR} 21$ expression, resulting in the suppression of proliferation and induction of apoptotic activity [128]. These results might pave the way for exploring non-surgical options for cholesteatoma management.

\section{Role of osteoclasts and other cells in bone resorption}

Osteoclast mediated bone resorption is the fundamental pathologic event in cholesteatoma. Whatever the factors that activate osteoclasts, recruitment of mononuclear precursors for osteoclasts and activation of osteoclastogenesis in the last station of those different factors $[48,129]$. Wide variety of factors had the ability to activate osteoclasts including substance $\mathrm{P}$ which promotes osteoclastogenesis via activation of NF-kappa B [69]. In addition, macrophage-colony stimulating factor, $\mathrm{OPG}$, and $\mathrm{OPG}$ ligand were found to be highly expressed in cholesteatoma specimens being released from activated T-cells in response to the inflammatory process in the cholesteatoma perimatrix and hence they promote osteoclastogenesis [130]. Other osteoclast stimulating factors include arachidonic acid metabolites, interleukins (IL- $1 \alpha, 1 \beta$, and IL-6), TNF- $\alpha$, interferon- $\beta$, and parathyroid-hormone related protein. Those factors are stimulated by local pressure exerted by cholesteatoma itself as well as the degree of inflammatory process $[48,129,131]$. Concerning other cells, Berger et al. [132] in 1985 investigated the role of mast cells and found a positive role of these cells in destructive potential in cholesteatoma. Furthermore, the cell mediated immunity appeared to have an essential role in cholesteatoma pathogenesis as well as its destructive behavior particularly T-lymphocytes. IHC studies of immune cell infiltrate in cholesteatoma tissue emphasized that T-cells (CD3, CD6), histiocytes (CD68) markers predominated in the stroma of cholesteatoma specimens as compared to control tissues $[133,134]$. The immune cells express toll like receptors 2,3 , and 4 which were studied in cholesteatoma tissue and revealed higher expression than normal skin [135].

\section{PREDICTORS FOR SEVERITY OF BONE RESORPTION}

Different molecules were investigated regarding their relation to the severity of bone resorption and occurrence of complications and a positive correlation were found between their expression in cholesteatoma tissues and the degree of bone erosion. These factors can be used as predictors for aggressiveness and recurrence of cholesteatoma and hence can be useful in determining
Table 2. Factors predicting the aggressive pattern of cholesteatoma as reported in literature

\begin{tabular}{ll}
\hline Factor's name & \multicolumn{1}{c}{ Authors \& year } \\
\hline Tumor necrosis factor-a & Sastry et al. (1999) [103] \\
& Yetiser et al. (2002) [106] \\
Interleukin-1a & Shiwa et al. (1995) [102] \\
& Yetiser et al. (2002) [106] \\
Matrix metalloproteinase-9 \& tenascin & Juhasz et al. (2009) [111] \\
MIB1 & Mallet et al. (2003) [82] \\
Bone morphogenic proteins & Oger et al. (2013) [124] \\
Amphiregulin & Macias et al. (2010) [83] \\
RANKL/OPGa) ratio & Jeong et al. (2006) [68] \\
\hline
\end{tabular}

a) Receptor activator of nuclear factor (NF)-kappa B, receptor activator of NF-kappa B ligand and osteoprotegerin.

the necessity and timing of intervention before occurrence of complications. These factors include TNF-alpha $[103,106]$, IL-1 $\alpha$ [102,106], MMP 9 and tenascin [111], amphiregulin [83], MIB1 [82], and BMPs [124]. Finally, RANKL/OPG ratio was considered to be a reliable index for bone erosion in cholesteatoma [68] (Table 2).

\section{IS THERE ANYTRIAL FOR NON-SURGICAL TREATMENT? 'FUTURE PROSPECTIVES'}

Until now, no medical treatment is available for cholesteatoma [1]. Research trials for non-surgical treatment of cholesteatoma are very limited. In a previous study, the role of antibiotic treatment was restricted in decreasing otorrhoea and other inflammation related symptoms in some cholesteatoma patients but the level of cytokines was not affected [106]. The presence of bacterial biofilms in infected cholesteatomas may explain its resistance to antibiotic treatment as well as recurrence of such infection [59]. New therapeutic approaches should focus on trial of drugs that block the activity of cytokines closely related to bone erosion chiefly TNF- $\alpha$, MMPs, and IL-1 and IL-6 $[108,136]$. Nevertheless, drugs that inhibit TNF- $\alpha$ activity, in diseases such as rheumatoid arthritis were not yet investigated in cholesteatoma [108]. An experimental animal study was conducted by Yoon et al. [137] to examine the effect of pamidronate sodium (known drug in the treatment of Paget's disease and osteoporosis), in inhibiting bone resorption of cholesteatoma yielded promising results.

Because HEX activity was proved to have an active role in bone resorption in the bony areas adjacent to cholesteatoma, Olszewska et al. suggested that medications which inhibit HEX activity such as iminocyclitols, can be used in cholesteatoma treatment but no trials were done [77]. In addition, molecules targeted to suppress proliferation and induce apoptotic activity like let 7a microRNA which was proved to have a vital role in the inhibition of growth and invasion of cholesteatoma keratino- 
cytes via downregulation of miR 21 expression can be used in the future treatment of cholesteatoma [128]. Moreover, drugs used for inhibition of osteoclastogenesis might be of great value in cholesteatoma management [130]. One of these drugs is zoledronic acid which was studied in a previous animal trial that revealed significant inhibition of osteoclastogenesis in a dose-dependent manner [138]. Finally, recently performed comprehensive genetic studies on differently expressed genes on cholesteatoma in comparison to the skin provided a genetic map for various cholesteatoma related transcripts including up and downregulated genes. Through this knowledge, targeting drug therapy might be accessed in the future $[139,140]$.

\section{CONCLUSION}

From the above mentioned data, extensive meritorious research work had been performed to disclose the real secrets behind human cholesteatoma formation, expansion as well as its destructive pattern. We see that there is an indigence to discover new therapeutic choices for cholesteatoma other than surgery which must be the main subject of future cholesteatoma research. Experimental animal studies using induced or spontaneous cholesteatoma should be in advance by the use of anti-growth or antiproliferative agents as well as apoptotic agents that may hinder cholesteatoma growth and minimize its destructive potential. These trials will not only provide a new hope for non-surgical treatment of cholesteatoma but also will improve our understanding concerning the pathogenesis of that disease. Also, searching for predictors of aggressiveness might give help to determine the proper timing of intervention and prevent occurrence of complications.

\section{CONFLICT OF INTEREST}

No potential conflict of interest relevant to this article was reported.

\section{REFERENCES}

1. Olszewska E, Wagner M, Bernal-Sprekelsen M, Ebmeyer J, Dazert S, Hildmann H, et al. Etiopathogenesis of cholesteatoma. Eur Arch Otorhinolaryngol. 2004 Jan;261(1):6-24.

2. Soldati D, Mudry A. Knowledge about cholesteatoma, from the first description to the modern histopathology. Otol Neurotol. 2001 Nov;22(6):723-30.

3. Dornelles C, Costa SS, Meurer L, Schweiger C. Some considerations about acquired adult and pediatric cholesteatomas. Braz J Otorhinolaryngol. 2005 Jul-Aug;71(4):536-45.

4. Kuo CL. Etiopathogenesis of acquired cholesteatoma: prominent theories and recent advances in biomolecular research. Laryngoscope. 2015 Jan;125(1):234-40.
5. Kuo CL, Shiao AS, Yung M, Sakagami M, Sudhoff H, Wang CH, et al. Updates and knowledge gaps in cholesteatoma research. Biomed Res Int. 2015;2015:854024.

6. Aquino JE, Cruz Filho NA, de Aquino JN. Epidemiology of middle ear and mastoid cholesteatomas: study of 1146 cases. Braz J Otorhinolaryngol. 2011 Jun;77(3):341-7.

7. Chole RA. The molecular biology of bone resorption due to chronic otitis media. Ann NYAcad Sci. 1997 Dec;830:95-109.

8. Louw L. Acquired cholesteatoma: summary of the cascade of molecular events. J Laryngol Otol. 2013 Jun;127(6):542-9.

9. Albino AP, Kimmelman CP, Parisier SC. Cholesteatoma: a molecular and cellular puzzle. Am J Otol. 1998 Jan;19(1):7-19.

10. Meyerhoff WL, Truelson J. Cholesteatoma staging. Laryngoscope. 1986 Sep;96(9 Pt 1):935-9.

11. Friedmann I. The comparative pathology of otitis media, experimental and human. II. The histopathology of experimental otitis of the guinea-pig with particular reference to experimental cholesteatoma. J Laryngol Otol. 1955 Sep;69(9):588-601.

12. Lepercque S, Broekaert D, Van Cauwenberge P. Cytokeratin expression patterns in the human tympanic membrane and external ear canal. Eur Arch Otorhinolaryngol. 1993;250(2):78-81.

13. Lee RJ, Mackenzie IC, Hall BK, Gantz BJ.The nature of the epithelium in acquired cholesteatoma. Clin Otolaryngol Allied Sci. 1991 Apr;16(2):168-73.

14. Imamura S, Nozawa I, Imamura M, Murakami Y. Pathogenesis of experimental aural cholesteatoma in the chinchilla. ORL J Otorhinolaryngol Relat Spec. 1999 Mar-Apr;61(2):84-91.

15. Persaud R, Hajioff D, Trinidade A, Khemani S, Bhattacharyya MN, Papadimitriou N, et al. Evidence-based review of aetiopathogenic theories of congenital and acquired cholesteatoma. J Laryngol Otol. 2007 Nov;121(11):1013-9.

16. Kuijpers W, Vennix PP, Peters TA, Ramaekers FC. Squamous metaplasia of the middle ear epithelium. Acta Otolaryngol. 1996 Mar; 116(2):293-8.

17. Akyildiz N,Akbay C, Ozgirgin ON, Bayramoglu I, Sayin N.The role of retraction pockets in cholesteatoma development: an ultrastructural study. Ear Nose Throat J. 1993 Mar;72(3):210-2.

18. Chole RA, Tinling SP. Basal lamina breaks in the histogenesis of cholesteatoma. Laryngoscope. 1985 Mar;95(3):270-5.

19. Sudhoff H, Bujia J, Borkowshi G, Koc C, Holly A, Hildmann H, et al. Basement membrane in middle ear cholesteatoma: immunohistochemical and ultrastructural observations. Ann Otol Rhinol Laryngol. 1996 Oct;105(10):804-10.

20. Sudhoff H, Linthicum FH Jr. Cholesteatoma behind an intact tympanic membrane: histopathologic evidence for a tympanic membrane origin. Otol Neurotol. 2001 Jul;22(4):444-6.

21. Magnan J, Chays A, Bremond G, De Micco C, Lebreuil G. Anatomopathology of cholesteatoma. Acta Otorhinolaryngol Belg. 1991; 45(1):27-34.

22. Kim CS, Chung JW. Morphologic and biologic changes of experimentally induced cholesteatoma in Mongolian gerbils with anticytokeratin and lectin study. Am J Otol. 1999 Jan;20(1):13-8.

23. Jackler RK, Santa Maria PL, Varsak YK, Nguyen A, Blevins NH. A new theory on the pathogenesis of acquired cholesteatoma: mucosal traction. Laryngoscope. 2015 Aug;125 Suppl 4:S1-14.

24. Wullstein HL, Wullstein SR. Cholesteatoma: etiology, nosology and tympanoplasty. ORL J Otorhinolaryngol Relat Spec. 1980;42(6): 313-35.

25. McKennan KX, Chole RA. Post-traumatic cholesteatoma. Laryngoscope. 1989 Aug;99(8 Pt 1):779-82.

26. Falk B, Magnuson B. Evacuation of the middle ear by sniffing: a cause of high negative pressure and development of middle ear disease. Otolaryngol Head Neck Surg. 1984 Jun;92(3):312-8.

27. Magnuson B, Falk B. Eustachian tube malfunction and middle ear 
disease in new perspective. J Otolaryngol. 1983 Jun;12(3):187-93.

28. Lindeman P, Holmquist J. Mastoid volume and eustachian tube function in ears with cholesteatoma. Am J Otol. 1987 Jan;8(1):5-7.

29. Wolfman DE, Chole RA. Osteoclast stimulation by positive middleear air pressure. Arch Otolaryngol Head Neck Surg. 1986 Oct;112 (10):1037-42.

30. Dominguez S, Harker LA. Incidence of cholesteatoma with cleft palate. Ann Otol Rhinol Laryngol. 1988 Nov-Dec;97(6 Pt 1):65960 .

31. Hornigold R, Morley A, Glore RJ, Boorman J, Sergeant R. The longterm effect of unilateral t-tube insertion in patients undergoing cleft palate repair: 20-year follow-up of a randomised controlled trial. Clin Otolaryngol. 2008 Jun;33(3):265-8.

32. Spilsbury K, Ha JF, Semmens JB, Lannigan F. Cholesteatoma in cleft lip and palate: a population-based follow-up study of children after ventilation tubes. Laryngoscope. 2013 Aug;123(8):2024-9.

33. Coker NJ, Jenkins HA, Fisch U. Obliteration of the middle ear and mastoid cleft in subtotal petrosectomy: indications, technique, and results. Ann Otol Rhinol Laryngol. 1986 Jan-Feb;95(1 Pt 1):5-11.

34. Roland NJ, Phillips DE, Rogers JH, Singh SD. The use of ventilation tubes and the incidence of cholesteatoma surgery in the paediatric population of Liverpool. Clin Otolaryngol Allied Sci. 1992 Oct;17 (5):437-9.

35. Marchioni D, Alicandri-Ciufelli M, Molteni G, Artioli FL, Genovese E, Presutti L. Selective epitympanic dysventilation syndrome. Laryngoscope. 2010 May;120(5):1028-33.

36. Marchioni D, Grammatica A, Alicandri-Ciufelli M, AggazzottiCavazza E, Genovese E, Presutti L. The contribution of selective dysventilation to attical middle ear pathology. Med Hypotheses. 2011 Jul;77(1):116-20.

37. Marchioni D, Mattioli F, Alicandri-Ciufelli M, Presutti L. Prevalence of ventilation blockages in patients affected by attic pathology: a case-control study. Laryngoscope. 2013 Nov;123(11):2845-53.

38. Palva T, Ramsay H. Incudal folds and epitympanic aeration. Am J Otol. 1996 Sep;17(5):700-8.

39. Palva T, Ramsay H, Bohling T. Tensor fold and anterior epitympanum.Am J Otol. 1997 May;18(3):307-16.

40. Huisman MA, de Heer E, Ten Dijke P, Grote JJ. Transforming growth factor beta and wound healing in human cholesteatoma. Laryngoscope. 2008 Jan;118(1):94-8.

41. Sudhoff H,Tos M. Pathogenesis of attic cholesteatoma: clinical and immunohistochemical support for combination of retraction theory and proliferation theory. Am J Otol. 2000 Nov;21(6):786-92.

42. Lim DJ, Saunders WH. Acquired cholesteatoma: light and electron microscopic observations. Ann Otol Rhinol Laryngol. 1972 Feb; 81(1):1-11.

43. Alves AL, Pereira CS, Ribeiro Fde A, Fregnani JH. Analysis of histopathological aspects in acquired middle ear cholesteatoma. Braz J Otorhinolaryngol. 2008 Nov-Dec;74(6):835-41.

44. Dornelles C, Meurer L, Selaimen da Costa S, Schweiger C. Histologic description of acquired cholesteatomas: comparison between children and adults. Braz J Otorhinolaryngol. 2006 Sep-Oct;72 (5):641-8.

45. Sade J, Halevy A. The aetiology of bone destruction in chronic otitis media. J Laryngol Otol. 1974 Feb;88(2):139-43.

46. Bretlau P, Sorensen CH, Jorgensen MB, Dabelsteen E. Bone resorption in human cholesteatomas. Ann Otol Rhinol Laryngol. 1982 Mar-Apr;91(2 Pt 1):131-5.

47. Kurihara A, Toshima M, Yuasa R, Takasaka T. Bone destruction mechanisms in chronic otitis media with cholesteatoma: specific production by cholesteatoma tissue in culture of bone-resorbing activity attributable to interleukin-1 alpha. Ann Otol Rhinol Laryngol. 1991 Dec;100(12):989-98.

48. Jung JY, Chole RA. Bone resorption in chronic otitis media: the role of the osteoclast. ORL J Otorhinolaryngol Relat Spec. 2002 Mar-Apr;64(2):95-107.

49. Maranhao A, Andrade J, GodofredoV, Matos R, Penido N. Epidemiology of intratemporal complications of otitis media. Int Arch Otorhinolaryngol. 2014 Apr;18(2):178-83.

50. Chole RA, McGinn MD, Tinling SP. Pressure-induced bone resorption in the middle ear. Ann Otol Rhinol Laryngol. 1985 MarApr;94(2 Pt 1):165-70.

51. McGinn MD, Chole RA, Tinling SP. Bone resorption induced by middle-ear implants. Arch Otolaryngol Head Neck Surg. 1986 Jun;112(6):635-41.

52. Orisek BS, Chole RA. Pressures exerted by experimental cholesteatomas. Arch Otolaryngol Head Neck Surg. 1987 Apr;113(4):38691.

53. Huang CC, Yi ZX, Yuan QG, Abramson M. A morphometric study of the effects of pressure on bone resorption in the middle ear of rats. Am J Otol. 1990 Jan;11(1):39-43.

54. Kaneko Y, Yuasa R, Ise I, lino Y, Shinkawa H, Rokugo M, et al. Bone destruction due to the rupture of a cholesteatoma sac: a pathogenesis of bone destruction in aural-cholesteatoma. Laryngoscope. 1980 Nov;90(11 Pt 1):1865-71.

55. Nguyen KH, Suzuki H, OhbuchiT, WakasugiT, Koizumi H, Hashida $\mathrm{K}$, et al. Possible participation of acidic $\mathrm{pH}$ in bone resorption in middle ear cholesteatoma. Laryngoscope. 2014 Jan;124(1):245-50.

56. Chen ZF, Darvell BW, Leung VW. Hydroxyapatite solubility in simple inorganic solutions. Arch Oral Biol. 2004 May;49(5):359-67.

57. Saunders J, Murray M, Alleman A. Biofilms in chronic suppurative otitis media and cholesteatoma: scanning electron microscopy findings. Am J Otolaryngol. 2011 Jan-Feb;32(1):32-7.

58. Gu X, Keyoumu Y, Long L, Zhang H. Detection of bacterial biofilms in different types of chronic otitis media. Eur Arch Otorhinolaryngol. 2014 Nov;271(11):2877-83.

59. Chole RA, Faddis BT. Evidence for microbial biofilms in cholesteatomas. Arch Otolaryngol Head Neck Surg. 2002 Oct;128(10):112933.

60. Lampikoski H, Aarnisalo AA, Jero J, Kinnari TJ. Mastoid biofilm in chronic otitis media. Otol Neurotol. 2012 Jul;33(5):785-8.

61. Van Snick J. Interleukin-6: an overview. Annu Rev Immunol. 1990;8:253-78.

62. Yellon RF, Leonard G, Marucha PT, Craven R, Carpenter RJ, Lehmann WB, et al. Characterization of cytokines present in middle ear effusions. Laryngoscope. 1991 Feb;101(2):165-9.

63. Peek FA, Huisman MA, Berckmans RJ, Sturk A, Van Loon J, Grote JJ. Lipopolysaccharide concentration and bone resorption in cholesteatoma. Otol Neurotol. 2003 Sep;24(5):709-13.

64. Ricciardiello F, Cavaliere M, Mesolella M, Iengo M. Notes on the microbiology of cholesteatoma: clinical findings and treatment. Acta Otorhinolaryngol Ital. 2009 Aug;29(4):197-202.

65. Nason R, Jung JY, Chole RA. Lipopolysaccharide-induced osteoclastogenesis from mononuclear precursors: a mechanism for osteolysis in chronic otitis. J Assoc Res Otolaryngol. 2009 Jun;10(2): 151-60.

66. Jung JY, Lee DH, Wang EW, Nason R, Sinnwell TM, Vogel JP, et al. P. aeruginosa infection increases morbidity in experimental cholesteatomas. Laryngoscope. 2011 Nov;121(11):2449-54.

67. Boyce BF, Xing L. Functions of RANKL/RANK/OPG in bone modeling and remodeling. Arch Biochem Biophys. 2008 May; 473(2):139-46.

68. Jeong JH, Park CW, Tae K, Lee SH, Shin DH, Kim KR, et al. Expression of RANKL and OPG in middle ear cholesteatoma tissue. Laryngoscope. 2006 Jul;116(7):1180-4.

69. Sohn SJ. Substance P upregulates osteoclastogenesis by activating nuclear factor kappa B in osteoclast precursors. Acta Otolaryngol. 2005 Feb;125(2):130-3. 
70. Sherman BE, Chole RA.A mechanism for sympathectomy-induced bone resorption in the middle ear. Otolaryngol Head Neck Surg. 1995 Nov;113(5):569-81.

71. Jung JY, Lin AC, Ramos LM, Faddis BT, Chole RA. Nitric oxide synthase I mediates osteoclast activity in vitro and in vivo. J Cell Biochem. 2003 Jun;89(3):613-21.

72. Jung JY, Pashia ME, Nishimoto SY, Faddis BT, Chole RA. A possible role for nitric oxide in osteoclastogenesis associated with cholesteatoma. Otol Neurotol. 2004 Sep;25(5):661-8.

73. Abramson M, Huang CC. Localization of collagenase in human middle ear cholesteatoma. Laryngoscope. 1977 May;87(5 Pt 1): 771-91.

74. Moriyama H, Honda Y, Huang CC, Abramson M. Bone resorption in cholesteatoma: epithelial-mesenchymal cell interaction and collagenase production. Laryngoscope. $1987 \mathrm{Jul} ; 97$ (7 Pt 1):854-9.

75. Lazarus GS, Jensen PJ. Plasminogen activators in epithelial biology. Semin Thromb Hemost. 1991 Jul;17(3):210-6.

76. Olszewska E, Borzym-Kluczyk M, Olszewski S, Rogowski M, Zwierz K. Hexosaminidase as a new potential marker for middle ear cholesteatoma. Clin Biochem. 2006 Nov;39(11):1088-90.

77. Olszewska E, Olszewski S, Borzym-Kluczyk M, Zwierz K. Role of $\mathrm{N}$-acetyl-beta-d-hexosaminidase in cholesteatoma tissue. Acta Biochim Pol. 2007;54(2):365-70.

78. Olszewska E, Jakimowicz-Rudy J, Knas M, Chilimoniuk M, Pietruski JK, Sieskiewicz A. Cholesteatoma-associated pathogenicity: potential role of lysosomal exoglycosidases. Otol Neurotol. 2012 Jun;33(4):596-603.

79. Hansen T, Unger RE, Gaumann A, Hundorf I, Maurer J, Kirkpatrick $\mathrm{CJ}$, et al. Expression of matrix-degrading cysteine proteinase cathepsin K in cholesteatoma. Mod Pathol. 2001 Dec;14(12):122631.

80. Sikka K, Sharma SC, Thakar A, Dattagupta S. Evaluation of epithelial proliferation in paediatric and adult cholesteatomas using the Ki-67 proliferation marker. J Laryngol Otol. 2012 May;126(5):4603.

81. Hamajima Y, Komori M, Preciado DA, Choo DI, Moribe K, Murakami S, et al. The role of inhibitor of DNA-binding (Id1) in hyperproliferation of keratinocytes: the pathological basis for middle ear cholesteatoma from chronic otitis media. Cell Prolif. 2010 Oct;43 (5):457-63.

82. Mallet Y, Nouwen J, Lecomte-Houcke M, Desaulty A. Aggressiveness and quantification of epithelial proliferation of middle ear cholesteatoma by MIB1. Laryngoscope. 2003 Feb;113(2):328-31.

83. Macias MP, Gerkin RD, Macias JD. Increased amphiregulin expression as a biomarker of cholesteatoma activity. Laryngoscope. 2010 Nov;120(11):2258-63.

84. Bujía J, Schilling V, Holly A, Stammberger M, Kastenbauer E. Hyperproliferation-associated keratin expression in human middle ear cholesteatoma. Acta Otolaryngol. 1993 May;113(3):364-8.

85. Schulz P, Bujía J, Holly A, Shilling V, Kastenbauer E. Possible autocrine growth stimulation of cholesteatoma epithelium by transforming growth factor alpha. Am J Otolaryngol. 1993 Mar-Apr;14 (2):82-7.

86. Bujia J, Sudhoff H, Holly A, Hildmann H, Kastenbauer E. Immunohistochemical detection of proliferating cell nuclear antigen in middle ear cholesteatoma. Eur Arch Otorhinolaryngol. 1996;253(1-2): 21-4.

87. Ergun S, Zheng X, Carlsoo B. Expression of transforming growth factor-alpha and epidermal growth factor receptor in middle ear cholesteatoma.Am J Otol. 1996 May;17(3):393-6.

88. Kojima H, Tanaka Y, Tanaka T, Miyazaki H, Shiwa M, Kamide Y, et al. Cell proliferation and apoptosis in human middle ear cholesteatoma.Arch Otolaryngol Head Neck Surg. 1998 Mar;124(3):261-4.

89. Shiwa M, Kojima H, Moriyama H. Expression of transforming growth factor-alpha (TGF-alpha) in cholesteatoma. J Laryngol Otol. 1998 Aug;112(8):750-4.

90. Kuczkowski J, Pawelczyk T, Bakowska A, Narozny W, Mikaszewski B. Expression patterns of Ki-67 and telomerase activity in middle ear cholesteatoma. Otol Neurotol. 2007 Feb;28(2):204-7.

91. Chae SW, Song JJ, Suh HK, Jung HH, Lim HH, Hwang SJ. Expression patterns of p27Kip1 and Ki-67 in cholesteatoma epithelium. Laryngoscope. 2000 Nov;110(11):1898-901.

92. Yamamoto-FukudaT,Takahashi H,Terakado M, Hishikawa Y, KojiT. Expression of keratinocyte growth factor and its receptor in noncholesteatomatous and cholesteatomatous chronic otitis media. Otol Neurotol. 2010 Jul;31(5):745-51.

93. Barbara M, Raffa S, Mure C, Manni V, Ronchetti F, Monini S, et al. Keratinocyte growth factor receptor (KGF-R) in cholesteatoma tissue. Acta Otolaryngol. 2008 Apr;128(4):360-4.

94. Lee SH, Jang YH, Tae K, Park YW, Kang MJ, Kim KR, et al.Telomerase activity and cell proliferation index in cholesteatoma. Acta Otolaryngol. $2005 \mathrm{Jul} ; 125(7): 707-12$.

95. Kim CS, Lee CH, Chung JW, Kim CD. Interleukin-1 alpha, interleukin-1 beta and interleukin-8 gene expression in human aural cholesteatomas. Acta Otolaryngol. 1996 Mar;116(2):302-6.

96. Jung TT, Juhn SK. Prostaglandins in human cholesteatoma and granulation tissue. Am J Otol. 1988 May;9(3):197-200.

97. Sugita T, Huang CC, Abramson M. The effect of endotoxin and prostaglandin E2 on the proliferation of keratinocytes in vitro. Arch Otorhinolaryngol. 1986;243(3):211-4.

98. Ahn JM, Huang CC, Abramson M. Localization of interleukin-1 in human cholesteatoma. Am J Otolaryngol. 1990 Mar-Apr;11(2): 71-7.

99. Yan SD, Huang CC. Tumor necrosis factor alpha in middle ear cholesteatoma and its effect on keratinocytes in vitro. Ann Otol Rhinol Laryngol. 1991 Feb;100(2):157-61.

100. Kakiuchi H, Kinoshita K, Katoh Y,Tabata T. Interleukin-1 of cholesteatomatous keratinocytes. Ann Otol Rhinol Laryngol Suppl. 1992 Oct;157:32-8.

101. Schilling V, Negri B, Bujia J, Schulz P, Kastenbauer E. Possible role of interleukin 1 alpha and interleukin 1 beta in the pathogenesis of cholesteatoma of the middle ear. Am J Otol. 1992 Jul;13(4):350-5.

102. Shiwa M, Kojima H, Kamide Y, Moriyama H. Involvement of interleukin-1 in middle ear cholesteatoma. Am J Otolaryngol. 1995 SepOct;16(5):319-24.

103. Sastry KV, Sharma SC, Mann SB, Ganguly NK, Panda NK. Aural cholesteatoma: role of tumor necrosis factor-alpha in bone destruction.Am J Otol. 1999 Mar;20(2):158-61.

104. Shibosawa E,Tsutsumi K, Takakuwa T,Takahashi S. Stromal expression of matrix metalloprotease-9 in middle ear cholesteatomas. Am J Otol. 2000 Sep;21(5):621-4.

105. Schmidt M, Grunsfelder P, Hoppe F. Up-regulation of matrix metalloprotease-9 in middle ear cholesteatoma: correlations with growth factor expression in vivo? Eur Arch Otorhinolaryngol. 2001 Nov; 258(9):472-6.

106. Yetiser S, Satar B, Aydin N. Expression of epidermal growth factor, tumor necrosis factor-alpha, and interleukin-1alpha in chronic otitis media with or without cholesteatoma. Otol Neurotol. 2002 Sep; 23(5):647-52.

107. Morales DS, Penido Nde O, da Silva ID, Stavale JN, Guilherme A, Fukuda Y. Matrix metalloproteinase 2: an important genetic marker for cholesteatomas. Braz J Otorhinolaryngol. 2007 Jan-Feb;73 (1):51-7.

108. Vitale RF, Ribeiro Fde A. The role of tumor necrosis factor-alpha (TNF-alpha) in bone resorption present in middle ear cholesteatoma. Braz J Otorhinolaryngol. 2007 Jan-Feb;73(1):117-21.

109.Juhn SK, Jung MK, Hoffman MD, Drew BR, Preciado DA, Sausen $\mathrm{NJ}$, et al. The role of inflammatory mediators in the pathogenesis of 
otitis media and sequelae. Clin Exp Otorhinolaryngol. 2008 Sep; 1(3):117-38.

110. Suchozebrska-Jesionek D, Szymanski M, Kurzepa J, Golabek W, Stryjecka-Zimmer M. Gelatinolytic activity of matrix metalloproteinases 2 and 9 in middle ear cholesteatoma. J Otolaryngol Head Neck Surg. 2008 Oct;37(5):628-32.

111.Juhasz A, Sziklai I, Rakosy Z, Ecsedi S, Adany R, Balazs M. Elevated level of tenascin and matrix metalloproteinase 9 correlates with the bone destruction capacity of cholesteatomas. Otol Neurotol. 2009 Jun;30(4):559-65.

112. Kuczkowski J, Sakowicz-Burkiewicz M, Izycka-Swieszewska E, Mikaszewski B, Pawelczyk T. Expression of tumor necrosis factor- $\alpha$, interleukin- $1 \alpha$, interleukin- 6 and interleukin-10 in chronic otitis media with bone osteolysis. ORL J Otorhinolaryngol Relat Spec. 2011;73(2):93-9.

113. Vitale RF, Pereira CS, Alves AL, Fregnani JH, Ribeiro FQ. TNF-R2 expression in acquired middle ear cholesteatoma. Braz J Otorhinolaryngol. 2011 Jul-Aug;77(4):531-6.

114. Rezende CE, Souto RP, Rapoport PB, Campos Ld, Generato MB. Cholesteatoma gene expression of matrix metalloproteinases and their inhibitors by RT-PCR. Braz J Otorhinolaryngol. 2012 Jun; 78(3):116-21.

115. Bertolini DR, Nedwin GE, Bringman TS, Smith DD, Mundy GR. Stimulation of bone resorption and inhibition of bone formation in vitro by human tumour necrosis factors. Nature. 1986 Feb;319 (6053):516-8.

116. Yan SD, Huang CC. The role of tumor necrosis factor-alpha in bone resorption of cholesteatoma. Am J Otolaryngol. 1991 Mar-Apr;12 (2):83-9.

117. Iino Y, Toriyama M, Ogawa H, Kawakami M. Cholesteatoma debris as an activator of human monocytes: potentiation of the production of tumor necrosis factor. Acta Otolaryngol. 1990 Nov-Dec;110 (5-6):410-5.

118. Postlethwaite AE, Lachman LB, Mainardi CL, Kang AH. Interleukin 1 stimulation of collagenase production by cultured fibroblasts. J Exp Med. 1983 Feb;157(2):801-6.

119. Sun J, Hemler ME. Regulation of MMP-1 and MMP-2 production through CD147/extracellular matrix metalloproteinase inducer interactions. Cancer Res. 2001 Mar;61(5):2276-81.

120.Sudhoff H, Dazert S, Gonzales AM, Borkowski G, Park SY, Baird A, et al. Angiogenesis and angiogenic growth factors in middle ear cholesteatoma. Am J Otol. 2000 Nov;21(6):793-8.

121. Fujioka O, Huang CC. Platelet-derived growth factor in middle ear cholesteatoma. Eur Arch Otorhinolaryngol. 1994;251(4):199-204.

122. Huang T, Yan SD, Huang CC. Colony-stimulating factor in middle ear cholesteatoma. Am J Otolaryngol. 1989 Nov-Dec;10(6):393-8.

123. Schmidt M, Schler G, Gruensfelder P, Hoppe F. Expression of bone morphogenetic protein-2 messenger ribonucleic acid in cholesteatoma fibroblasts. Otol Neurotol. 2002 May;23(3):267-70.

124. Oger M, Alpay HC, Orhan I, Onalan EE, Yanilmaz M, Sapmaz E. The effect of BMP-2, BMP-4 and BMP-6 on bone destruction of cholesteatoma presence. Am J Otolaryngol. 2013 Nov-Dec;34(6): 652-7.

125. Sheikholeslam-Zadeh R, Decaestecker C, Delbrouck C, Danguy A,
Salmon I, ZickY, et al. The levels of expression of galectin-3, but not of galectin-1 and galectin-8, correlate with apoptosis in human cholesteatomas. Laryngoscope. 2001 Jun;111(6):1042-7.

126. Olszewska E, Chodynicki S, Chyczewski L. Apoptosis in the pathogenesis of cholesteatoma in adults. Eur Arch Otorhinolaryngol. 2006 May;263(5):409-13.

127. Chung JH, Lee SH, Park CW, Kim KR, Tae K, Kang SH, et al. Expression of Apoptotic vs Antiapoptotic Proteins in Middle Ear Cholesteatoma. Otolaryngol Head Neck Surg. 2015 Dec;153(6):102430.

128.Zhang W, Chen X, Qin Z. MicroRNA let-7a suppresses the growth and invasion of cholesteatoma keratinocytes. Mol Med Rep. 2015 Mar;11(3):2097-103.

129. Chole RA. Cellular and subcellular events of bone resorption in human and experimental cholesteatoma: the role of osteoclasts. Laryngoscope. 1984 Jan;94(1):76-95.

130.Hamzei M, Ventriglia G, Hagnia M, Antonopolous A, BernalSprekelsen M, Dazert S, et al. Osteoclast stimulating and differentiating factors in human cholesteatoma. Laryngoscope. 2003 Mar; 113(3):436-42.

131. Cheshire IM, Blight A, Ratcliffe WA, Proops DW, Heath DA. Production of parathyroid-hormone-related protein by cholesteatoma cells in culture. Lancet. 1991 Oct;338(8774):1041-3.

132.Berger G, Hawke M, Ekem JK. Bone resorption in chronic otitis media: the role of mast cells. Acta Otolaryngol. 1985 Jul-Aug;100 (1-2):72-80.

133. Schilling V, Bujia J, Negri B, Schulz P, Kastenbauer E. Immunologically activated cells in aural cholesteatoma. Am J Otolaryngol. 1991 Sep-Oct;12(5):249-53.

134. Hussein MR, Sayed RH, Abu-Dief EE. Immune cell profile in invasive cholesteatomas: preliminary findings. Exp Mol Pathol. 2010 Apr;88(2):316-23.

135.Szczepanski M, Szyfter W, Jenek R, Wrobel M, Lisewska IM, Zeromski J. Toll-like receptors 2, 3 and 4 (TLR-2, TLR-3 and TLR-4) are expressed in the microenvironment of human acquired cholesteatoma. Eur Arch Otorhinolaryngol. 2006 Jul;263(7):603-7.

136. Schonermark M, Mester B, Kempf HG, Blaser J, Tschesche H, Lenarz T. Expression of matrix-metalloproteinases and their inhibitors in human cholesteatomas. Acta Otolaryngol. 1996 May;116 (3):451-6.

137. Yoon TH, Lee SH, Park MH, Chung JW, Kim HJ. Inhibition of cholesteatomatous bone resorption with pamidronate disodium. Acta Otolaryngol. 2001 Jan;121(2):178-81.

138. Sudhoff H, Jung JY, Ebmeyer J, Faddis BT, Hildmann H, Chole RA. Zoledronic acid inhibits osteoclastogenesis in vitro and in a mouse model of inflammatory osteolysis. Ann Otol Rhinol Laryngol. 2003 Sep;112(9 Pt 1):780-6.

139. Klenke C, Janowski S, Borck D, Widera D, Ebmeyer J, Kalinowski J, et al. Identification of novel cholesteatoma-related gene expression signatures using full-genome microarrays. PLoS One. 2012;7(12): e52718.

140. Macias JD, Gerkin RD, Locke D, Macias MP. Differential gene expression in cholesteatoma by DNA chip analysis. Laryngoscope. 2013 Oct;123 Suppl S5:S1-21. 